\title{
Rebound stridor in children with croup after nebulised adrenaline: does it really exist?
}

Laryngotracheobronchitis is a common childhood illness affecting 3\% of children. Most of the affected children are aged between 6 months and 3 years, with a peak incidence of 60 per 1000 child-years in those children aged between 1 and 2 years [1]. Epidemiological studies suggest that $1-5 \%$ of children with croup are admitted to hospital and $2-3 \%$ of those admitted children, require intubation [2]. Death is extremely rare and has been estimated to occur in no more than 1 in 30000 cases [2]. Parainfluenza (types 1 and 3), and influenza $A$ and $B$ are the most common viral agents causing croup. Respiratory syncytial virus (RSV), rhinovirus, coronavirus, metapneumovirus and adenovirus are also responsible for this illness. There is seasonality to the prevalence with more presentations in the autumn. There is an annual pattern influenced by the variability of the viruses in the community for that year [2].

Croup is characterised by a "barking" cough, hoarse voice, stridor and respiratory distress caused by generalised airway inflammation and oedema of the upper airway mucosa. Most children have mild illness which resolves spontaneously without any specific treatment. However, some children have severe illness with stridor, respiratory distress and hypoxaemia requiring intubation. Current evidence strongly supports the use of glucocorticoids for the management of croup [3]. Previously it was felt that steroids took up to $6 \mathrm{~h}$ to have an effect on the airway [4], but a recent Cochrane review concluded that glucocorticoids improve croup symptoms at $2 \mathrm{~h}$ with the effect lasting at least $24 \mathrm{~h}$ [3]. Glucocorticoids also reduce rates of return visits, admissions and readmissions. When treated with placebo, 204 out of every 1000 children will return for medical care. When treated with glucocorticoids, 74-153 out of every 1000 children will return for medical care [3]. Glucocorticoids reduce the length of stay by $15 \mathrm{~h}$ (range 6-24 h), but make no difference to the need for additional treatments. Dexamethasone $0.15 \mathrm{mg} \cdot \mathrm{kg}^{-1}$ or prednisolone $1 \mathrm{mg} \cdot \mathrm{kg}^{-1}$ would be the recommended treatment dosing [2], although other guidelines suggest doses up to $0.6 \mathrm{mg} \cdot \mathrm{kg}^{-1}$ of dexamethasone [3].

Nebulised adrenaline/epinephrine is recommended for use in severe and life-threatening croup [5], although some guidelines use it for those children with moderate symptoms [6]. Nebulised adrenaline has been associated with a clinically and statistically significant transient reduction in croup symptoms 30 min post-treatment [5] and can "buy time" for steroids to act. Children with croup develop swelling of inner mucosal layers of the larynx and trachea. Nebulised adrenaline is thought to act by stimulating $\alpha$-adrenergic receptors in subglottic mucous membranes, producing vasoconstriction and decreased mucosal oedema. The clinical effect is sustained for at least $1 \mathrm{~h}$, but disappears after $2 \mathrm{~h}$. Studies of nebulised adrenaline treatment of croup have used both racemic and L-adrenaline. One small trial found that L-adrenaline $(5.0 \mathrm{~mL}$, $0.1 \%(1: 1000)$ ) was as effective and safe as racemic adrenaline (0.5 mL, 2.25\%) [7]. When racemic and $\mathrm{L}$-adrenaline are compared, there is no difference in croup score at $30 \mathrm{~m}$ (standardised mean difference $0.33,95 \% \mathrm{Cl}-0.42-1.08)$, but at $2 \mathrm{~h}$ L-adrenaline shows a small reduction in croup score compared
Cite as: Sakthivel M, Elkashif S, Al Ansari K, et al. Rebound stridor in children with croup after nebulised adrenaline: does it really exist? Breathe 2019; 15: e1-e7.

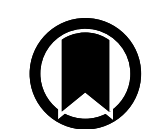

CrossMark 
with racemic adrenaline (standardised mean difference $0.87,95 \% \mathrm{Cl} 0.09-1.65$ ) [5].

There is a widespread belief amongst clinicians that such treatment can cause rebound phenomenon [8]. This was first suggested in 1978 [8] and 40 years on, continues to be mentioned as a possibility in publications in 2018 [1].

Rebound is defined as a temporary deviation from a normal state in the opposite direction following an abrupt removal or discontinuation of a variable, such as a treatment suddenly discontinued after long-term use, a passive resistance that is released suddenly, an undershoot in an effort to restore balance or homeostasis, or a condition wherein the maximum therapeutic effect is reached and the opposite effect ensues [9]. The rebound phenomenon occurs when the sudden discontinuation of a medication results in the relapse of symptoms that are worse than those before the treatment. Examples of rebound phenomenon include Stewart-Holmes test for cerebellar lesions [10] and Somogyi phenomenon [11].

We hypothesise that children with croup, following treatment with nebulised adrenaline may develop re-emergence of their initial symptoms, which are milder than at initial presentation and no worse than at baseline and that rebound of symptoms in croup does not occur after treatment with nebulised adrenaline. We performed a literature search to ascertain the degree of re-emergence symptoms and to determine if it were worse than baseline. The search was completed independently by two authors (M.S. and S.E.).

\section{Search question}

Do children with croup (patient group) when treated with nebulised adrenaline (intervention) develop re-emergence of stridor, worse than the initial baseline presentation (comparison) as defined by changes in symptoms score (outcome)?

\section{Search strategy}

Secondary sources: the Cochrane library was searched in September 2018 with the terms Croup and Adrenaline OR Epinephrine. One relevant review [5] was identified. The review included eight studies. Primary sources: MEDLINE was searched via PubMed using following terms Croup OR Laryngitis AND Adrenaline OR Epinephrine OR rebound stridor. Inclusion criteria were that studies included children between the ages of 0 and 18 years. 41 clinical trials were retrieved. A further two studies [12, 13] were considered relevant, in addition to the eight studies included in the Cochrane review. Summaries of the papers are presented in the table 1.

\section{Discussion}

The management of children with croup has had several controversies over the decades. In 1988 a review by COURIEL [21] emphasised the lack of high-quality studies to aid management. Nebulised adrenaline was advocated only in children with impending airway obstruction, due to the transient improvement and possibility of rebound. The benefit of steroids in the management was not clearly established at that time and hence most early studies compared treatments of nebulised adrenaline with placebo or racemic adrenaline versus L-adrenaline.

LENNY and MILNER [8] proposed the possibility of rebound phenomenon in children with acute viral croup treated with a nebulised $\alpha$-adrenergic stimulant. The authors studied the total airway resistance before and after administration of nebulised phenylephrine in eight children. Prior to nebulisation, two drops of $0.05 \%$ xylometazoline were instilled in each nostril to ensure full nasal patency and children were sedated with $80 \mathrm{mg} \cdot \mathrm{kg}^{-1}$ chloral hydrate. Seven out of eight children who were treated with nebulised phenylephrine showed improvement clinically and in terms of airway resistance. One child who did not show improvement was later was diagnosed with acute epiglottitis. The authors reported that improvement was transient and the airway resistance returned to pre-treatment levels within 30 min, which was hypothesised as a possible rebound phenomenon.

Over the following 40 years, the 10 studies identified here are very reassuring in that rebound does not exist and that although symptoms may return after the use of nebulised adrenaline, no study has reported the symptoms as being worse than baseline. If steroids are used as well then, as their effect starts to impact the upper airway at $2 \mathrm{~h}$ post-administration, this reduces any re-emergence of symptoms post-adrenaline as that effect wears off after 1-2 h.

A small underpowered study from 1973 by GARDNER et al. [20], reported before the advent of the widespread use of steroids, was a retrospective review and this, not surprisingly, failed to substantiate a decrease in either hospitalisation or symptoms resulting from treatment with nebulised adrenaline. They did, however, acknowledge that adrenaline may be of therapeutic value in some patients with croup depending on the aetiological agent but may simply be the addition of moisture to the airways.

Three small studies [17-19], involving 48 children in total, showed significant initial improvement using nebulised adrenaline compared to placebo with some return of symptoms but no rebound reported. The following studies started using steroids in their design and recruited larger numbers but in children with more severe croup. No rebound of symptoms is described and an effect of the 


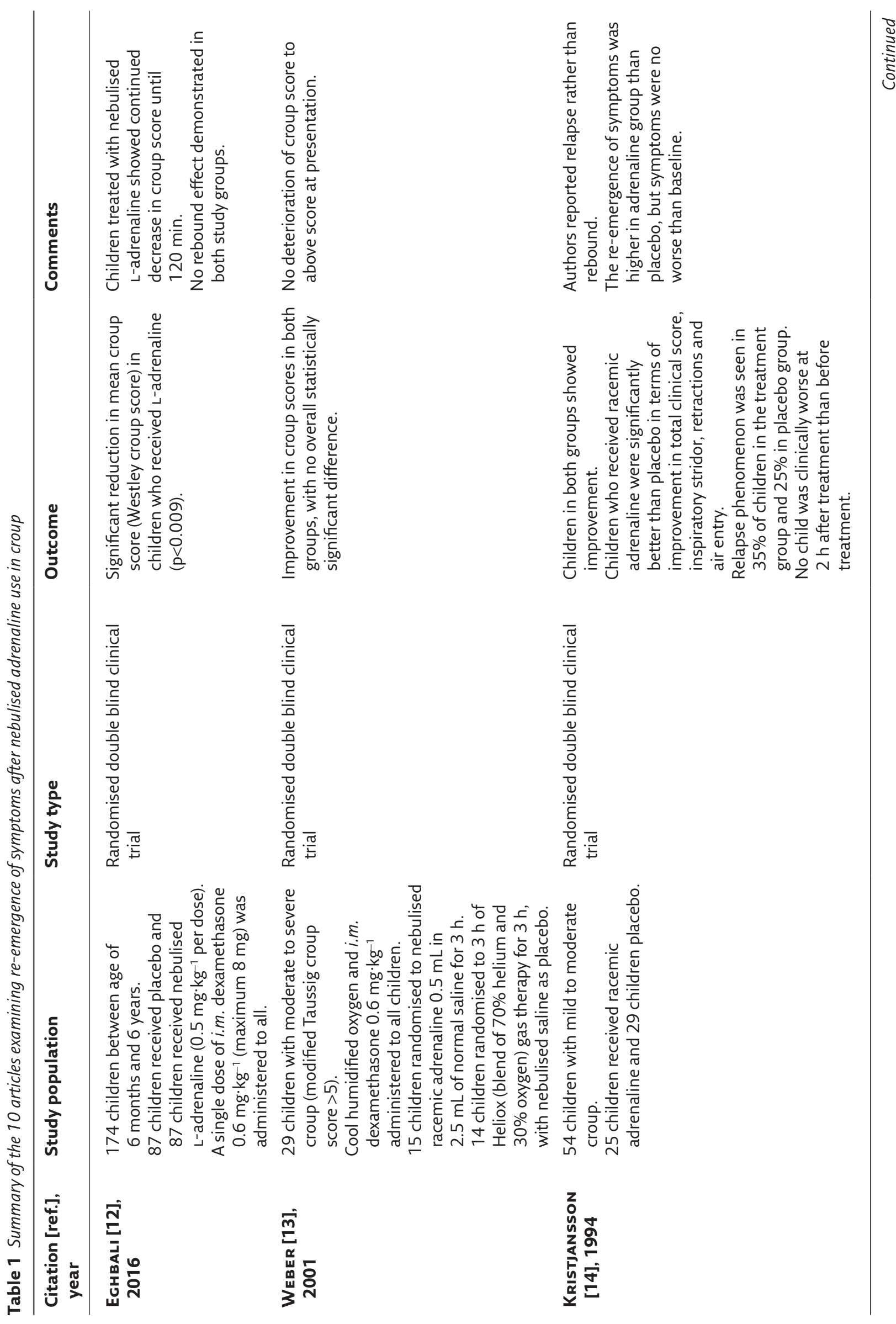




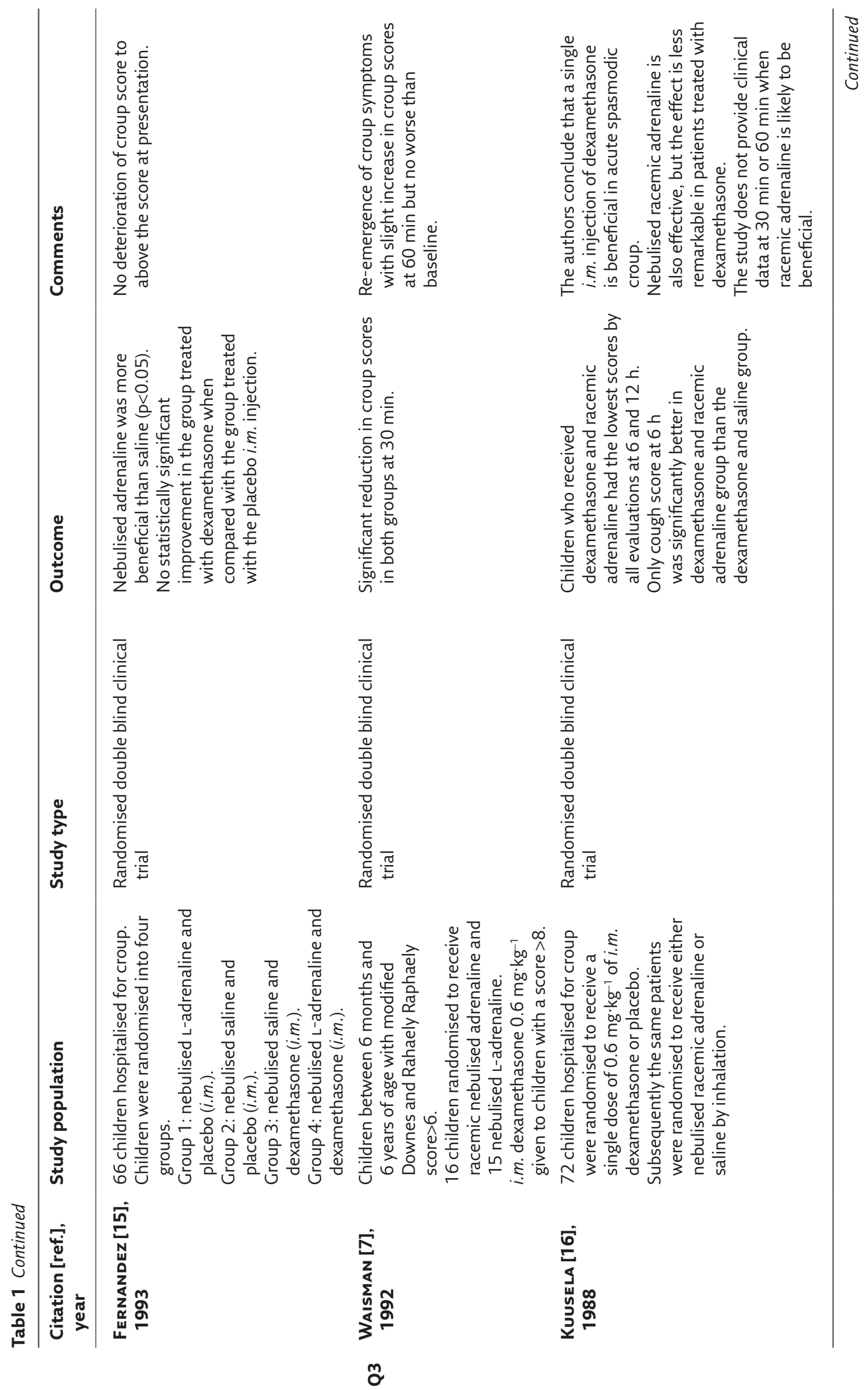




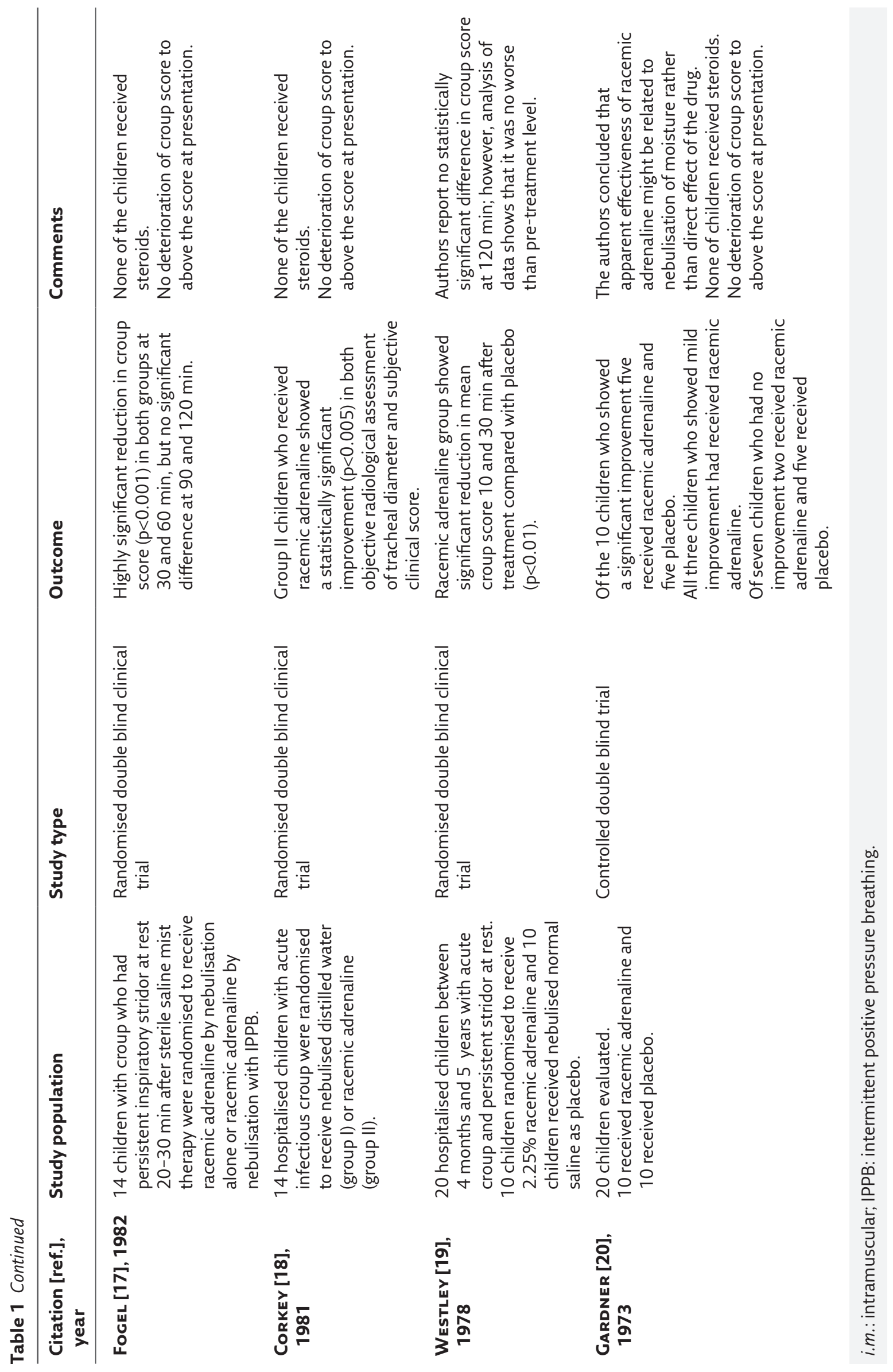


steroids reducing any re-emergence of symptoms is becoming clearer [7, 15, 16] (see table 1).

KRISTJANSSON et al. [14] reported re-emergence of symptoms in $35 \%$ of children receiving nebulised adrenaline and in $25 \%$ of children receiving placebo. No steroids were used. They posited that it is not likely that the phenomenon is related to adrenaline only, but rather to ongoing inflammation and oedema in the airway. They concluded that nebulised adrenaline is effective for the treatment of acute mild to moderately severe croup and that it should be used as a first line treatment [14] This has not been taken up universally, but it is now standard practice in some countries to use steroids and nebulised adrenaline in the emergency department, watch the patients for $2 \mathrm{~h}$ and then discharge home if well enough [2]. The final two studies both used steroids and nebulised adrenaline, showing clearly a good response to the treatment with no rebound or indeed any major re-emergence of symptoms [12, 13].

The data presented here are reassuring in that re-emergence of symptoms may occur but is no worse than baseline. The re-emergence of symptoms is less marked in studies when children received concurrent steroids.

So, in answer to the proposed question: "Do children with croup (patient group) when treated with nebulised adrenaline (intervention) develop re-emergence of stridor, worse than initial baseline presentation (comparison) as defined by changes in symptoms score (outcome)?" Or "Rebound stridor in children with croup after nebulised adrenaline: does it really exist?" The answer is no.

\section{Key points}

- Children with croup who are treated with nebulised adrenaline may develop re-emergence of symptoms, but they are not worse than baseline. They do not have rebound phenomenon.

- The re-emergence of symptoms after treatment with nebulised adrenaline is less pronounced in children who had concurrent treatment with oral or parenteral glucocorticoids. Hence children who have had moderate to severe croup receiving nebulised adrenaline should be given oral or parenteral glucocorticoids.

\section{Affiliations}

\section{Muthukumar Sakthivel ${ }^{1,2}$, Sami Elkashif1, Khalid Al Ansari ${ }^{1,2,3}$, Colin V.E. Powell ${ }^{1,4}$}

1 Paediatric Emergency Dept, Sidra Medicine, Doha, Qatar. ${ }^{2}$ Dept of Clinical Paediatrics, Weill Cornell Medical College, Ar-Rayyan, Qatar. ${ }^{3}$ Paediatric Emergency Centers, Doha, Qatar. ${ }^{4}$ Child Health, School of Medicine, Cardiff University, Cardiff, UK.

\section{Conflict of interest}

None declared.

\section{References}

1. Geelhoed G. Chapter 6.4 Croup. In: Cameron P, Browne G, Biswadev M, et al., eds. Textbook of Paediatric Emergency Medicine. 3rd Edn. London, Elsevier, 2019.

2. Bjornson CL, Johnson DW. Croup in children. CMAJ 2013; 185 1317-1323.

3. Gates A, Gates M, Vandermeer B, et al. Glucocorticoids for croup in children. Cochrane Database Syst Rev 2018; 8: CD001955.

4. Parker R, Powell CV, Kelly AM. How long does stridor at rest persist in croup after the administration of oral prednisolone. Emerg Med Australas 2004; 16: 135-138.

5. Bjornson C, Russell K, Vandermeer B, et al. Nebulized epinephrine for croup in children. Cochrane Database Syst Rev 2013; 10: CD006619.

6. Borland ML, Babl FE, Sheriff N, et al. Croup management in Australia and New Zealand: a PREDICT study of physician practice and clinical practice guidelines. Pediatr Emerg Care 2008; 24: 452-456

7. Waisman Y, Klein BL, Boenning DA, et al. Prospective randomized double-blind study comparing L-epinephrine and racemic epinephrine aerosols in the treatment of laryngotracheitis (croup). Pediatrics 1992; 89: 302-306.

8. Lenny W, Milner A D. Treatment of acute viral croup. Arch Dis Child 1978; 53: 704-706.

9. Biology-Online Dictionary. Rebound Phenomenon. www.biologyonline.org/dictionary/Rebound_phenomenon Date last updated: July 13, 2012. Date last accessed: October 14, 2018.

10. Waubant E, Tezenas du Montcel S, Jedynak C, et al Multiple sclerosis tremor and the Stewart-Holmes manoeuvre. Mov Disord 2003; 18: 948-952.

11. Rybicka M, Krysiak R, Okopień B. The dawn phenomenon and the Somogyi effect - two phenomena of morning hyperglycaemia. Endokrynol Pol 2011; 62: 276-283.

12. Eghbali A, Sabbagh A, Bagheri B, et al. Efficacy of nebulized L-epinephrine for treatment of croup: a randomized, double-blind study. Fundam Clin Pharmacol 2016; 30: 70-75

13. Weber JE, Chudnofsky CR, Younger JG, et al. A randomized comparison of helium-oxygen mixture (heliox) and racemic epinephrine for the treatment of moderate to severe croup. Pediatrics 2001; 107: e96. 
14. Kristjansson S, Berg-Kelly K, Winso E. Inhalation of racemic adrenaline in the treatment of mild and moderately severe croup. Clinical symptom score and oxygen saturation measurements for evaluation of treatment effects. Acto Paediatr 1994; 83: 1156-1160.

15. Fernandez MA, Gonzalez SE, Etxefarria RI, et al. Randomized double blind study of treatment of croup with adrenaline and/ or dexamethasone in children. An Esp Pediatr 1993; 38: 29-32.

16. Kuusela AL, Vesikari T. A randomized double blind, placebocontrolled trial of dexamethasone and racemic epinephrine in the treatment of croup. Acta Paediatr Scand 1988; 77: 99-104.

17. Fogel JM, Berg IJ, Gerber MA, et al. Racemic epinephrine in the treatment of croup: nebulization alone versus nebulization with intermittent positive pressure breathing. J Pediatr 1982; 101: 1028-1031.

18. Corkey C, Barker G, Edmonds J, et al. Radiographic tracheal diameter measurements in acute infectious croup: an objective scoring system. Crit Care Med 1981; 9: 587-590.

19. Westley C, Ross C, Brooks J. Nebulized racemic epinephrine by IPPB for the treatment of croup: a doubleblind study. Am J Dis Child 1978; 132: 484-487.

20. Gardner HG, Powell KR, Roden VJ, et al. The evaluation of racemic epinephrine in the treatment of infectious croup. Pediatrics 1973; 52: 52-55.

21. Couriel JM. Management of croup. Arch Dis Child 1988; 63: $1305-1308$. 